\title{
Analysis of Amino Acids and Biogenic Amines during the Fermentaition of Jianghong Yulu
}

\author{
Qi Ningli \\ Chinese Academy of Tropical Agricultural Sciences \\ Center for Food Quality Supervision and Testing \\ Ministry of Agriculture \\ Zhanjiang, China \\ e-mail: qiqi120518@163.com
}

\section{Gong Xiao}

Chinese Academy of Tropical Agricultural Sciences Agricultural Product Processing Research Institute Zhanjiang, China

e-mail: yiyesuifeng@126.com

\author{
Yuan Xiaoli \\ Chinese Academy of Tropical Agricultural Sciences \\ South Subtropical Crops Research Institute \\ Zhanjiang, China \\ e-mail: 42839221@qq.com
}

\begin{abstract}
Objective: Jianghong yulu is a traditional seasoning produced through the salting and fermentation of fresh Harengula Zunasi Bleeker in Suixi, South of Guangdong in China. The manufacturing process is quite complex, including two stages, namely brining and spontaneous fermentation. In this work, the physicochemical properties were studied. 2. Methods: Amino acids and biogenic amines as the most important precursors of flavor development in Jianghong yulu were analyzed using chromatographic methods. 3. Results: One-way ANOVA analysis showed that the type and content of amino acids has undergone significant changes during the natural process. 4. Conclusion: The results are effective for better understanding the flavor formation and quality controlling of traditional Chinese fermented foods.
\end{abstract}

Keywords-Jianghong yulu; flavor development; amino acids; biogenic amines; quality controlling

\section{INTRODUCTION}

Yulu, also known as 'nampla' in Thailand, 'nucmam' in Vietnam, 'patis' in the Philippines, and 'shottsuru' in Japan, is a traditional seasoning produced through the fermentation of salted fish or shrimp by naturally occurring bacteria and fungi at high salt content 20\%-30\%, with a fermentation period in excess of 3 months or more, and has been consumed as an important condiment in various cuisines in Southeast and East Asia (Fukui et al., 2012; Park et al., 2001).

Jianghong yulu, traditionally made from Harengula Zunasi Bleeker and sea salt in a sealing terrine, is one of the most representative and characteristic seafood seasoning in Guangdong.

\author{
Liu Yangyang \\ Chinese Academy of Tropical Agricultural Sciences \\ Agricultural Product Processing Research Institute \\ Zhanjiang, China \\ e-mail: hws082319@163.com
}

\author{
Zhu Yiting \\ College of food science and technology \\ Huazhong Agricultural University \\ Wuhan, China \\ e-mail: zhuyiting_1990@163.com
}

It is necessary to investigate the microbial communities and physicochemical properties in the view of commercial importance. Until now, Achromobacter, Salimicrobium, Kocuria, Pseudoalteromonas, Bacillus, Micrococcus, Vibrio, Staphylococcus, Streptococcus, Tetragenococcus, and Holomonas were identified and/or isolated from spontaneous fermentation of salted seafood (Jiang et al., 2013). More recently, yulu has been produced commercially by local firms with some slightly different procedures. At the same time, it has received much more attention due to its potential carcinogenicity with relatively high biogenic amines content, whose formation is usually related to the microbial metabolic process (Zaman et al., 2009; Zhai et al., 2012). However, the chemical composition of yulu is different among countries, and its quality is mainly affected by the ingredients used, which could be different varieties of fish, the microflora involved in the environment, and fermentation process. However, no study has been carried out to investigate the flavor development of Jianghong yulu, and physiochemical properties have not been studied.

Amino acids are the most important nitrogen compounds in yulu, and have important functions in both nutrition and health, they are key precursors for syntheses of hormones and low-molecular weight nitrogenous substances with each having enormous biological importance. They are also precursors of some volatile compounds, such as higher alcohols, aldehydes, esters and ketonic acids, which make up the majority of aroma (Wang et al., 2014).

Biogenic amines (BAs) are basic nitrogenous compounds of low molecular weight with aliphatic or aromatic structure that are mainly formed through 
decarboxylation of amino acids. Most of them have strong physiological effects and play an important biological role as sources of nitrogen and precursors for the synthesis of hormones, alkaloids, nucleic acids, and proteins. Small amounts of BAs are generally bio-synthesized in plant and animal cells, and larger quantities are found as a consequence of microbial metabolism in a wide range of fermented foods. BAs partially contribute to food aroma during food processing. It is important to note, however, it is also potential precursors for the formation of carcinogenic N-nitroso compounds. When excessive amount of BAs was ingested with food, the human body generally showed distinctive toxic effects, such as headache, nausea, palpitations, blood pressure changes, respiratory disorder, and even anaphylactic shock (Stadler etal., 2008).

For these reasons, amino acids and biogenic amines are important for the flavor development of Jianghong yulu. In this work, they were analyzed throughout the fermentation process, which will provide more effective information for quality control.

\section{Materials and methods}

\section{A. Preparation of Jianghong yulu and sampling}

Jianghong yulu is usually produced during February. In this study, Harengula Zunasi Bleeker, caught off the Jianghong gulf located in South of China in Guangdong province, were kept in ice on board and transported to Jianghong town within $3 \mathrm{~h}$ after catch. Immediately used for yulu fermentation.

Each fish sample was mixed with solar salt at a ratio 7:3. Each mixture $(5 \mathrm{~kg})$ was then packed in a 6 -L glass jar (17-cm dia; $27-\mathrm{cm}$ height) and occupied about $90 \%$ of total jar volume. Each jar was covered with a glass plate. Fermentation was carried out at ambient temperature $\left(28{ }^{\circ} \mathrm{C}\right.$ to $\left.32{ }^{\circ} \mathrm{C}\right)$ for $52 \mathrm{wk}$ nd occupied about $90 \%$ of total jar volume.

During the naturally fermentation, samples of Jianghong yulu prepared in the same year using traditional homemade method were collected. Samples (30 to $40 \mathrm{~g}$ ) were taken at each time interval and centrifuged at 8000 rpm (PK 121R, ALC Intl. Srl, Cologno Monzese, Italy) at $4^{\circ} \mathrm{C}$ for $10 \mathrm{~min}$.

\section{B. Amino acid profiles of Jianghong yulu mash}

In the amino acid analysis, the lyophilized Jianghong yulu mash was hydrolyzed in $6 \mathrm{M} \mathrm{HCl}$ for $24 \mathrm{~h}$. Amino acids were quantified using the Hitachi L8800 amino acid analyzer (Hitachi High-Technologies Co., Tokyo, Japan) employing sodium citrate buffers as step gradients with the cation exchange postcolumn ninhydrin derivatization method. The data were described as grams of amino acid per $100 \mathrm{~g}$ of sample (Chou et al., 2015).

\section{Biogenic amines of Jianghong yulu mash}

Five grams of food samples was homogenized in a plastic beaker with $0.4 \mathrm{M} \mathrm{HClO}_{4}$ for $5 \mathrm{~min}$. The slurry was centrifuged at $4{ }^{\circ} \mathrm{C}$ for $10 \mathrm{~min}$ at $1800 \times \mathrm{g}$ and then filtered through a filter paper. The residue was extracted twice, the supernatants were combined and the volume was set to $25 \mathrm{~mL}$ with $\mathrm{HClO}_{4}$ (Šimat \& Dalgaard, 2011).

Derivatization of BAs was prepared according to the method of Ben-Giglrey (Ben-Giglrey et al., 1998). Briefly, one milliliter of the extract was spiked with $100 \mu \mathrm{L}$ of internal standard solution (1,7-heptanediamine) and mixed in a plastic test tube with $200 \mu \mathrm{L}$ of $2.0 \mathrm{M}$ sodium hydroxide, $300 \mu \mathrm{L}$ of saturated sodium bicarbonate, and $2.0 \mathrm{~mL}$ of dansyl chloride solution $(10 \mathrm{mg} / \mathrm{mL}$ dansyl chloride in acetone). After thoroughly overtaxing, the test tube was incubated for $45 \mathrm{~min}$ in a water bath at $40{ }^{\circ} \mathrm{C}$ with continuous shaking in darkness. Subsequently, 100 $\mu \mathrm{L}$ of $25 \%$ ammonium hydroxide was added to each sample for removing residual dansyl chloride. The mixture was complemented to $5.0 \mathrm{~mL}$ with acetonitrile after the resulting solution was left for $30 \mathrm{~min}$ at room temperature. Finally, the supernatant was filtered through membrane glass fiber filters $(0.22 \mu \mathrm{m}$, Millipore membrane). The quantitative analysis of amines was separated on $\mathrm{UPC}_{2}$ methond with a HSS $\mathrm{C}_{18} \mathrm{SB}$ column $(3.0 \times 100 \mathrm{~mm}, 1.7 \mu \mathrm{m}$, Waters, USA) as reporded by Gong with some modifications (Gong et al., 2014). The elution gradient (eluent $\mathrm{A}, \mathrm{CO}_{2}$; eluent $\mathrm{B}$, nhexane:isopropanol:ammonium hydroxide $=70: 30: 0.25$, $\mathrm{v} / \mathrm{v} / \mathrm{v}$ ) was: started at $2 \% \mathrm{~B}$; increased via linear gradient to $30 \% \mathrm{~B}$ at $5 \mathrm{~min}$, and $2 \% \mathrm{~B}$ at $7.2 \mathrm{~min}$. The back pressure was set at $1880 \mathrm{psi}$. The flow rate was kept at 2.0 $\mathrm{ml} / \mathrm{min}$, column temperature at $50{ }^{\circ} \mathrm{C}$, detection wavelength at $254 \mathrm{~nm}$ with compensation from 300 to 500 $\mathrm{nm}$, and the injection volume was $1.0 \mu \mathrm{L}$. Data processing was performed using Empower 3.0 software.

\section{Statistical analysis}

Statistical analysis was performed with SPSS 17.0 software (SPSS Inc, Chicago). All data were expressed as mean of at least three determinations for each sample, $\mathrm{n}=$ number of samples.

\section{RESULTS}

\section{A. Qualitative analysis of amino acids}

Fig. 1 shows the typical chromatographic profile of amino acid in Jianghong yulu mash at 570 and $440 \mathrm{~nm}$. It suggested that the amino acid was efficiency separated, which allowed perfect identification and quantification of amino acids in yulu mash.

During the fermentation process (from stage 1 to 2), the hydrolysis of protein occurs under the action of microorganisms and enzymes, and significant increase in the free amino acids free was observed except glutamate (Table 1). However, the proportion of different amino acids is different after fermentation, with a range of increase from 14 fold (lysine) to 2.01 fold (cystine) were found, which is closely related to changes and raw materials, fermentation conditions and the environment in the microflora and resulting to complex flavors of the yulu. 

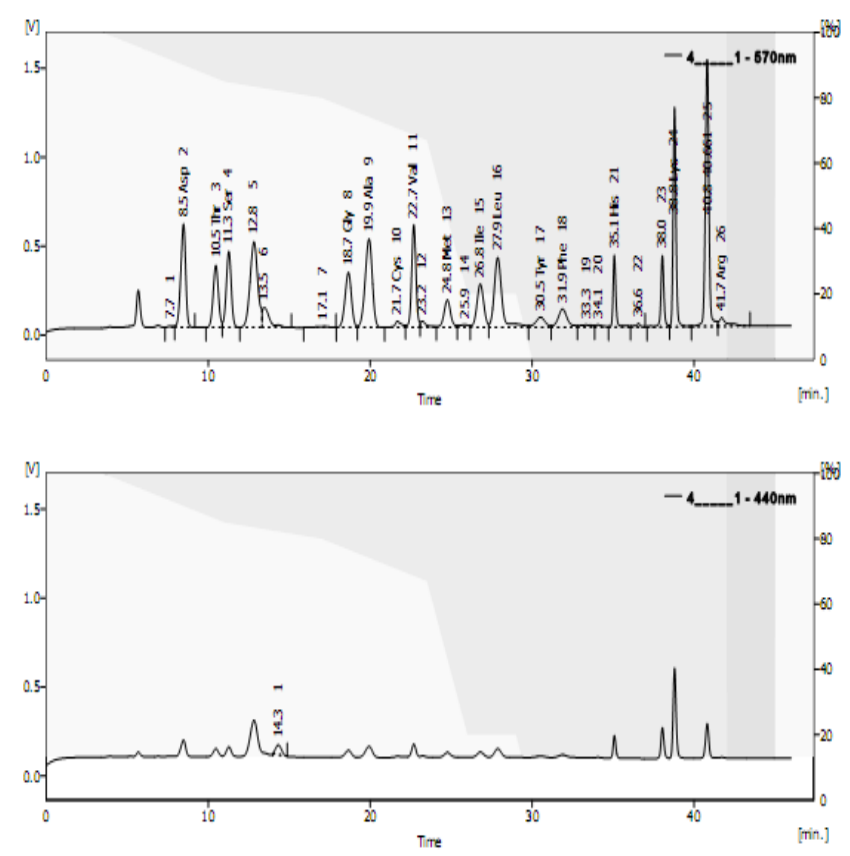

Figure I. Chromatograms of amino acid in Jianghong yulu mash.

Amino acids are important to maintain human life activities substance, which not only has a variety of physiological functions, but most amino acids and their salts have sweet, bitter or sour flavor. Glutamic acid, aspartic acid, phenylalanine, alanine, glycine, and tyrosine can exhibit special taste called umami amino acids. Glutamate is a natural amino acid in the flavor of the strongest material, followed by aspartic acid and its sodium salt. In South of China, traditional fermented yulu products could play an important role in improving food flavor and nutritional reinforcement of our diet.

TABlE 1. AMINO ACIDS CONTENTS (MG $100 \mathrm{G}^{-1}$ ) IN THE SELECTED JIANGHONG YULU SAMPLES.

\begin{tabular}{|l|c|c|}
\hline \multirow{2}{*}{ Amino acids } & \multicolumn{2}{|c|}{ Fermentation periods (n = 3) } \\
\cline { 2 - 3 } & Stage 1 & Stage 2 \\
\hline Aspartic acid & $1.23 \pm 0.04$ & $11.61 \pm 0.12 \mathrm{a}$ \\
\hline Threonine & $0.54 \pm 0.01$ & $6.55 \pm 0.04 \mathrm{a}$ \\
\hline Serine & $0.48 \pm 0.02$ & $6.66 \pm 0.04 \mathrm{a}$ \\
\hline Glycine & $0.58 \pm 0.01$ & $4.39 \pm 0.09 \mathrm{a}$ \\
\hline Alanine & $0.65 \pm 0.03$ & $9.37 \pm 0.24 \mathrm{a}$ \\
\hline Cystine & $0.59 \pm 0.06$ & $1.19 \pm 0.12 \mathrm{a}$ \\
\hline Valine & $0.92 \pm 0.11$ & $7.76 \pm 0.10 \mathrm{a}$ \\
\hline Methionine & $0.43 \pm 0.08$ & $4.59 \pm 0.10 \mathrm{a}$ \\
\hline Isoleucine & $0.55 \pm 0.04$ & $6.57 \pm 0.08 \mathrm{a}$ \\
\hline Leucine & $0.93 \pm 0.05$ & $12.10 \pm 0.16 \mathrm{a}$ \\
\hline Tyrosine & $0.45 \pm 0.03$ & $3.06 \pm 0.09 \mathrm{a}$ \\
\hline Phenylalanine & $0.54 \pm 0.02$ & $4.77 \pm 0.21 \mathrm{a}$ \\
\hline Histidine & $0.79 \pm 0.04$ & $4.72 \pm 0.06 \mathrm{a}$ \\
\hline Lysine & $1.00 \pm 0.03$ & $14.77 \pm 0.22 \mathrm{a}$ \\
\hline Arginine & $0.71 \pm 0.02$ & $1.90 \pm 0.06 \mathrm{a}$ \\
\hline Glutarnine & $1.65 \pm 0.01$ & - \\
\hline
\end{tabular}

a. "a" indicate significant difference

b. “-“", not detected.

\section{B. Qualitative analysis of biogenic amines}

Fig. 2 shows the typical chromatographic profile of the mixture of standard solutions of the eight BAs and internal standard (IS). It suggested that the derivatization used in this work allowed perfect identification and quantification of BAs. Analysis of food samples takes $10 \mathrm{~min}$ for a full column-balancing.
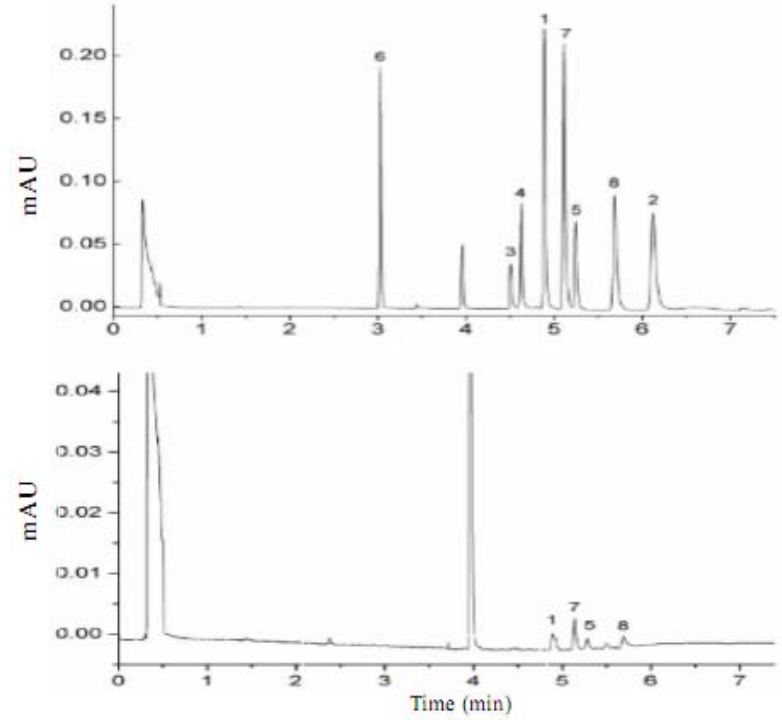

Figure II. Separation of standard mixture and yulu sample of biogenic amines as dansylamides. Peaks numbering: 1-spermine, 2-spermidine, 3 tyramine, 4-tryptamine, 5-putrescine, 6-phenylethylamine, 7-cadaverine, 8-histamine, and IS-1,7-heptanediamine.

The most important BAs found in the selected foods are histamine, cadaverine, phenylalanine, and putrescine was the major biogenic amines in Jianghong Yulu, and their contents significantly increased from stage 1 to 2 , with the range of 5.26 to $32.64 \mathrm{mg} / \mathrm{kg}$ (Table 2). However, tyramine was not detected after fermentation. It suggested that cadaverine and putrescine provides a reliable indictor of the degree of food freshness and spoilage, and histamine can be regarded as poisoning indictor. The results indicated the changes of good hygienic quality with negligible contents from toxicological point of view, the composition and content of eight biogenic amines in the selected samples are varied among different process periods and batches for evaluated.

TABLE 2. BIOBENIC AMINES CONTENTS (MG 1000 G-1) IN THE SELECTED JIANGHONG YULU SAMPLES.

\begin{tabular}{|l|c|c|}
\hline \multirow{2}{*}{ Biogenic amines } & \multicolumn{2}{|c|}{ Fermentation periods (n = 3) } \\
\cline { 2 - 3 } & Stage 1 & Stage 2 \\
\hline Spermine & $0.83 \pm 0.04$ & $17.25 \pm 0.67 \mathrm{a}$ \\
\hline Tyramine & $2.11 \pm 1.18$ & - \\
\hline Putrescine & $1.58 \pm 0.02$ & $20.75 \pm 0.28 \mathrm{a}$ \\
\hline Cadaverine & $0.71 \pm 0.12$ & $32.64 \pm 0.86 \mathrm{a}$ \\
\hline Histamine & $1.67 \pm 0.24$ & $23.43 \pm 2.89 \mathrm{a}$ \\
\hline phenylethylamine & $6.94 \pm 0.98$ & $8.19 \pm 0.12 \mathrm{a}$ \\
\hline tyramine & $6.41 \pm 1.90$ & $7.76 \pm 0.10 \mathrm{a}$ \\
\hline spermidine & - & $5.26 \pm 0.93 \mathrm{a}$ \\
\hline Phenylalanine & $6.02 \pm 1.48 \mathrm{a}$ & $11.60 \pm 2.41 \mathrm{a}$ \\
\hline
\end{tabular}

Although the average content for each amine is within the level limit that may elicit direct adverse reactions, 
consumers should be aware of the potential synergistic effect among different amines and limit their consumption at daily diet. Therefore, the analysis of BAs is necessary in order to evaluate their toxicological risk. Anyway, the information obtained in this work will also be useful for quality control of traditional Chinese fermented foods in future.

\section{Discussion}

Yulu is one major type of traditional fermented foods in China. In recent years, many national enterprises take local specialty as a development point. In this research those enterprises can have a greater awareness and understanding of local products, and it can also help to popularize traditional foods and further develop local foods. The formation of biogenic amines and changes in the amino acids are closely related.

Intervention in the fermentation process is essential, the desired effect can be achieved by controlling the degree of hydrolysis of amino acids to suppress the generation of biogenic amines, which is important for the protection of Jianghong yulu and has a practical meaning.

\section{ACKNOWLEDGMENT}

This work was financially supported by grants from the Fundamental Scientific Research Funds for Chinese Academy of Tropical Agricultural Sciences (Project No. 1630062015021), and we thanks Dai Qingpeng for the supply of Jianghong yulu samples.

\section{REFERENCES}

[1] C. H. Chou, C. W. Liu, D. J. Yang, Y. H. S. Wu, Y. C. Chen. 2015. "Amino acid, mineral, and polyphenolic profiles of black vinegar, and its lipid lowering and antioxidant effects in vivo," Food Chem, vol. 168, pp. 63-69. July 2015.
[2] Y. Fukui, M. Yoshida, K. i. Shozen, Y. Funatsu, T. Takano, H Oikawa, Y. Yano, M. Satomi. "Bacterial communities in fish sauce mash using culture-dependent and-independent methods," J Gen Appl Microbiol, vol. 58, pp. 273-281. Apr 2012.

[3] J. N. Park, Y. Fukumoto, E. Fujita, T. Tanaka, T. Washio, S. Otsuka, T. Shimizu, K. Watanabe, H. Abe. "Chemical composition of fish sauces produced in Southeast and East Asian countries," J Food Compos Anal, vol. 14, pp. 113-125. Apr 2001.

[4] M. Z. Zaman, A. Abdulamir, F. A. Bakar, J. Selamat, J. Bakar. "Microbiological, physicochemical and health impact of high level of biogenic amines in fish sauce," American Journal of Applied Sciences, vol. 6, pp. 1199-1211. 2009

[5] H. Zhai, X. Yang, L. Li, G. Xia, J. Cen, H. Huang, S. Hao "Biogenic amines in commercial fish and fish products sold in southern China," Food Control, vol. 25, pp. 303-308. May 2012.

[6] V. Šimat, and P. Dalgaard. "Use of small diameter column particles to enhance HPLC determination of histamine and other biogenic amines in seafood,". LWT-Food Sci Technol, vol. 44, pp. 399-406. Aug 2011.

[7] B. Ben-Giglrey, J. M. Vieites Baptista de Sousa, T. G. Villa and V. Barros. "Changes in biogenic amines and microbiological analysis in Albacore (Thunnus alalunga) muscle during frozen storage," Journal of Food Protection, vol. 61, pp. 608-615. May 1998.

[8] X. Gong, N. L. Qi, X. X. Wang, L. J. Lin, J. H. Li. "Ultraperformance convergence chromatography (UPC ${ }^{2}$ ) method for the analysis of biogenic amines in fermented foods,". Food Chem, vol. 162, pp. 172-175. Nov 2014.

[9] W. Jiang, Y. Xu, C. S. Li, X. Y. Dong and D. F. Wang. "Biogenic amines in commercially produced Yulu, a Chinese fermented fish sauce," Food Addit \& Contm B, vpl. 7, pp. 1-5. Jul 2014

[10] Y. Q. Wang, D. Q. Ye, B. Q. Zhu, G. F. Wu, C. Q. Duan. "Rapid HPLC analysis of amino acids and biogenic amines in wines during fermentation and evaluation of matrix effect," Food Chem, vol. 16, pp. 6-15. Nov 2014.

[11] Kalač, P., \& Krausová, P. "A review of dietary polyamines: Formation, implications for growth and health and occurrence in foods," Food Chem, vol. 90, pp. 219-230. Mar 2005.

[12] R. H. Stadler and D. R. Lineback. "Process-induced food toxicants: occurrence, formation, mitigation, and health risks," 1st ed. New Jersey: John Wiley \& Sons. 2008 